\title{
IRRIGATION PATTERN IN IMPROVED BRANCH CANALS
}

\author{
Evelin S .Yassa and T.T. El-Gamal \\ Water Management Research Institute, National Water Research Center
}

\begin{abstract}
The objective of this study is to verify the actual irrigation pattern in improved distributary canals which are operated under continuous flow. The study was applied in Dakalt canal, which is an improved canal in Mit Yazid command area. The study analysed water levels at different locations of the canal for six seasons from summer 2005 to winter 2007/2008. In addition, the study analysed the intensive collected water levels, actual supply discharges, actual withdrawal discharges during two field experiments which were conducted during winter 2006/2007 and summer 2007. The results illustrated the filling and the emptying periods in the canal during the day and the influence of the change in withdraw density on the fluctuation of water levels. The study showed that the irrigation hours were between 6:00 am and 7:00 pm during summer season and between 8:00 am to 7:00 pm for most of the reaches during winter season. During some summer periods, and when withdraw was continuing during the whole day, the withdraw ratios from 7:00 am to 7:00 pm were about $81.7 \%$ and $80.5 \%$ of total withdrawal volumes in the first and the second reaches respectively. The study also showed that average actual water levels were below the design water levels for most of the time during summer season due to the overcrowding of irrigations. Low water levels may make farmers dissatisfied and always complainant especially at end reaches. Supply discharge values were not allocated by equitable manner along the canal reaches and this is likely because there was no internal rotation between lifting points. The current study helps achieving the required design water levels in the next phases of the improvement project by applying internal rotations between single point lifting stations on the canal and its sub branches based on actual pattern of irrigation, which was illustrated in this study. That will enhance operation of improved canals and maximize the benefits of canal improvements.
\end{abstract}

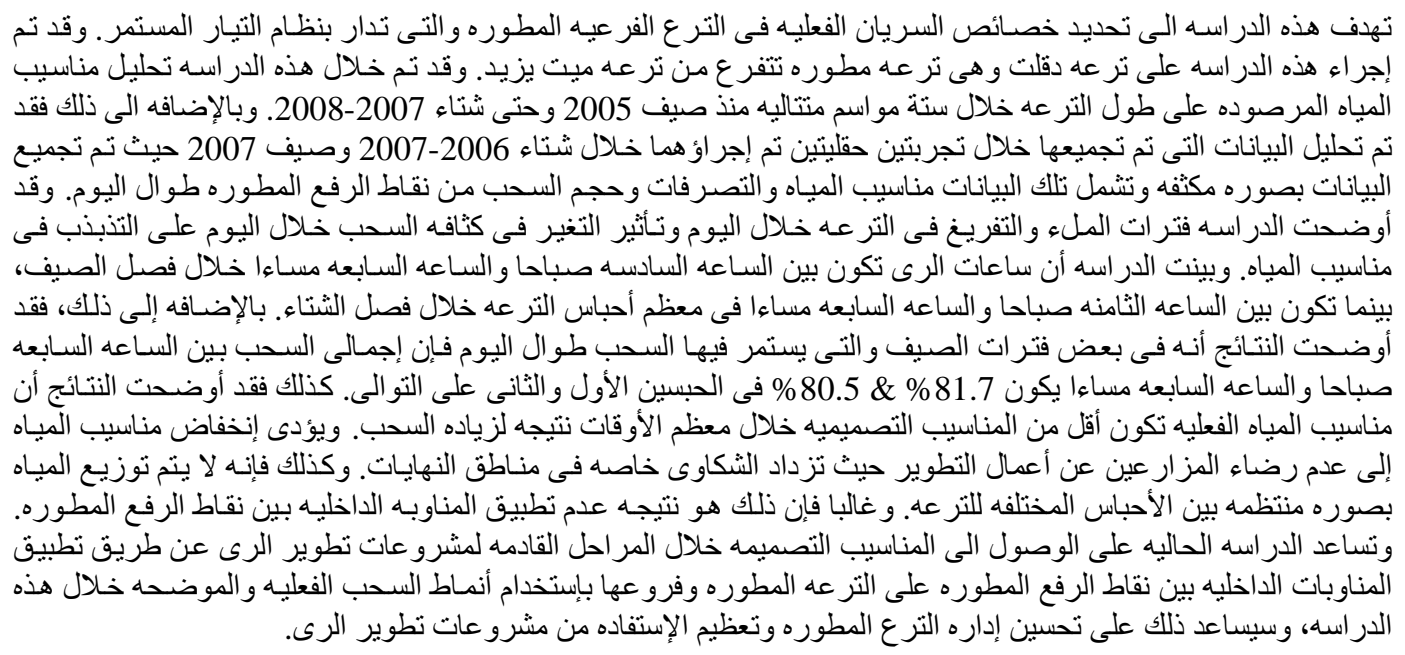

Keywords: Irrigation water allocation, irrigation system, continuous flow, irrigation pattern, distributary canals

\section{INTRODUCTION}

The irrigation delivery system in Egypt was designed to apply rotation flow. The application of the rotational system has begun in the nineteenth century with the beginning of the perennial irrigation system. According to L.Tinsley et al. (1984) [8], "irrigation rotations are commonly used in many countries where water is provided to a large number of small farmers and there are periods of water shortage 
during the year". They added "the irrigation rotation system was developed in Egypt to facilitate the equitable distribution of limited and varied amount of water". The "on/off" sequence of the rotation system is designed to provide distributary canals with sufficient amount of water while allowing continuous flow in main canals. The rotational system in Egypt includes double rotations, when "on" periods equal to "off" periods and triple rotations, when "on" periods equal to half of "off" periods. During on periods water is released to distributary canals with scheduled constant water levels downstream canals' intakes and tail ends without adjustments between light hours and night hours. Actual water levels are not constant; they fluctuated due to withdrawal by farmers (W.F. Mankarious, 1990) [13]. Water levels drawdown during light hours and rise during night hours. During light hours farmers scramble to irrigate so that they complain from water shortage, and during night hours there is water surplus at the canal tail end when farmers want not to irrigate. There is conflict between farmers and the irrigation districts (Abdel Fattah Metawie, 1989) [1]. Since the end of 1970's the attempt to apply continuous flow in the branch canals was introduced during EWUP (Egypt Water Use and management Project). Continuous flow was introduced by the meaning of reducing the cross sections of branch canals to provide water in smaller rates and continuous duration (El-Kady et al. ,1983) [5]. This experiment was re-discussed during EWUP and the authors argued that the application of continuous flow was not practical due to the enlargement of branch canals' cross-sections as "it would be extremely costly to renovate these canals for non-rotation i.e. continuous flow system" .With the end of EWUP period, the lifting methods have changed rapidly from sakias to mobile diesel pumps. This gave the farmers the chance to concentrate the irrigation during the day hours. In UNDP (United Nation Development Project), it was stated "In summer, there is a very pronounced peak of demand on the early morning. It seems that the morning peak reflects not only farmers' preferred time of irrigation, but also a desire to take advantage of water, which has refilled the canals during night. The ability of farmers to compete in this way is undoubtedly related to high rate of pump usage rather than sakias". Since UNDP time, the concept of night storage was introduced. Under this concept, night hours are considered as filling period to face high demand during day hours. Automatic gates were introduced to stop water from spilling to drains and the enlargement of the cross sections became not a constraint for the application of continuous flow.

"The concept of continuous flow means continuous availability of water, not more water. Single point lifting and scheduling along mesqas facilitate the even spread of water consumption" (Hvidt, 1998)
[7]. Continuous availability of water was defined during the design of improved canals by maximum and minimum water levels at upstream and downstream ends of the canals reaches. That reflects the limits of filling and emptying periods, respectively. However, the results of monitoring the improved system (WMRI, 2008) [14] showed that water is not available continuously at the different reaches of the improved canals and especially at the tail end regions. The disability to provide water continuously adversely affected the operation of the improved canals. Low water levels with different water shortage events at the tail ends increase the pumping cost, increase the conflict between farmers and make it difficult to develop and follow specific schedule between lifting points. The objective of this study is to monitor the actual irrigation pattern and its effect on the fluctuation of water levels in improved distributary canals. The actual abstracting pattern of irrigation could be taken into consideration to enhance the operation of distributary canals.

\section{CASE STUDY}

A typical distributary canal, Dakalt canal, was chosen for the current study (Figure 1). Dakalt offtakes from the right side of Mit Yazid canal at km 41.070. The canal length is $11.420 \mathrm{~km}$ and it irrigates about 5400 feddans. Design bed widths of Dakalt canal vary between $5 \mathrm{~m}$ and $2 \mathrm{~m}$, and the maximum design water levels vary between (3.40) and (1.05). Dakalt has 18 sub-branches which serve around 3708 feddans. The lengths of these branches are between 0.1 and $3.11 \mathrm{~km}$ and their cultivated areas are between 30 and 556 feddans. By surveying the canal, the cross sections are within or below the old design cross sections for the most of the canal, (Figures 2 \& 3).

Dakalt has two old lifting cross regulators at $\mathrm{km}$ 2.865, and 5.575 in addition to the intake one. With the implementation of IIP, three downstream control

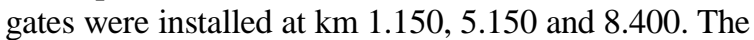
canal has no distributor and according to McDonald (1988) [9], "it was decided not to install the distributor, but to use Dakalt as a pilot for applying continuous flow using lifting gates for discharge regulation". Regularly, there was a big head difference around the head regulator except for some small periods where the gate was free open. The implementation of IIP also includes installing 74 lifting points on the canal; 23 of them were installed on the main stream of the canal and 51 were installed on the sub-branches. Number of lifting points on different sub-branches is between 1 and 11 lifting points. 


\section{METHODOLOGY}

The current study collected and analysed different irrigation data on Dakalt canal regions with focusing on the head and the tail regions. From surveying it was found that, the head region which covers from $\mathrm{km} 1.15$ to $\mathrm{km} \mathrm{5.15}$. it services 3123 feddans. This region has eleven sub-branches and seven lifting points on the main stream. This includes 45 lifting points with 101 pumps. Also the middle region is from $\mathrm{km} 5.575$ to $\mathrm{km} \mathrm{8.400,} \mathrm{it} \mathrm{has} \mathrm{five} \mathrm{sub-branches}$ and five lifting points on the main stream it serves 592 feddans as an improved area. This region has an unimproved sub-branch, 13 lifting points and 26 pumps. The tail region is from $\mathrm{km} 8.400$ to $\mathrm{km}$ 11.420. It contains one unimproved sub-branch and eleven lifting points on the main canal. The served area for improved lifting points is 433 feddans.

The collected data include:

\section{Water levels}

Automatic water level recorders were installed at the upstream end of canal reaches and at different locations on the canal. Water levels were recorded every 30 minutes continuously for six seasons, from summer 2005 to winter 2007/2008.

\section{Actual withdrawal data}

Two experiments were conducted, each experiment continued for a week. One was implemented during winter (November / 2006) and the other was implemented during summer (June / 2007).Single point lifting stations on branches and direct irrigation off takes were surveyed along each reach. For each station, the location, area served and hourly working pumps were surveyed. The design discharges of pumps in single point lifting stations are 60 and 90 1/s. Design discharges of pumps are considered to calculate withdrawal discharges for a reach. Withdrawal discharges of each reach during the twenty four hours of a day were calculated as shown

$$
\mathrm{Qr}_{\mathrm{dh}}=\left(\sum_{\mathrm{i}=\mathrm{n}}^{\mathrm{i}=1} \mathrm{q}_{1}+\sum_{\mathrm{i}=\mathrm{z}}^{\mathrm{i}=1} \mathrm{q}_{2}\right) / 1000
$$

Where:

$\mathrm{Qr}_{\mathrm{dh}}$ is the total discharge for a reach in a day hour $\left(\mathrm{m}^{3} / \mathrm{sec}\right.$.).

$\mathrm{n}, \mathrm{z}$ are a number of working pumps with discharge 60 and 90 l/s respectively, and.

$\mathrm{q}_{1}$ and $\mathrm{q}_{2}$ are the considered pump discharges,60 \& $90 \mathrm{l} / \mathrm{s}$ respectively.

In many times for the third reach during the experiments, only five lifting points from the eleven were in service. The collected data during the experiments concerned the improved lifting points and it ignored farmers' pumps. Farmers cannot irrigate from the lifting points because of low water availability and therefore they use their own pumps.

\section{Discharges}

Actual discharges at the upstream end of each reach were measured during the experiments twice daily at am and pm periods. The am and pm periods were from 8:00 to 9:00 am and from 2:00 to 3:00 pm, respectively. Average discharge values for am and pm periods were considered for calculating daily actual discharges.

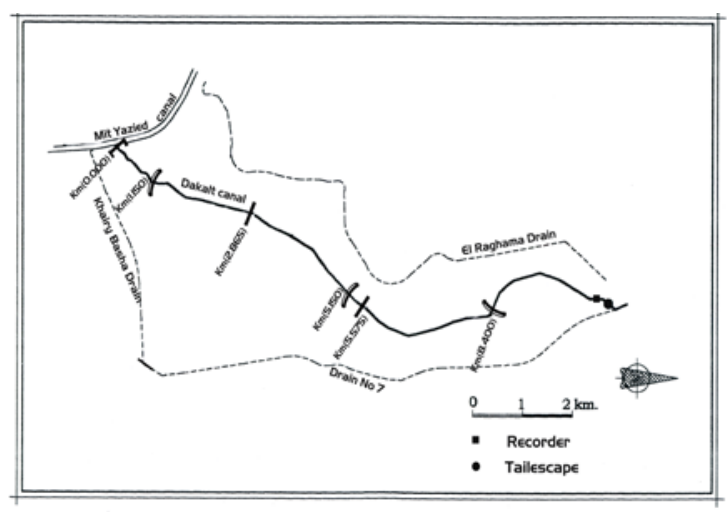

Fig. 1 Schematic drawing for Dakalt command area

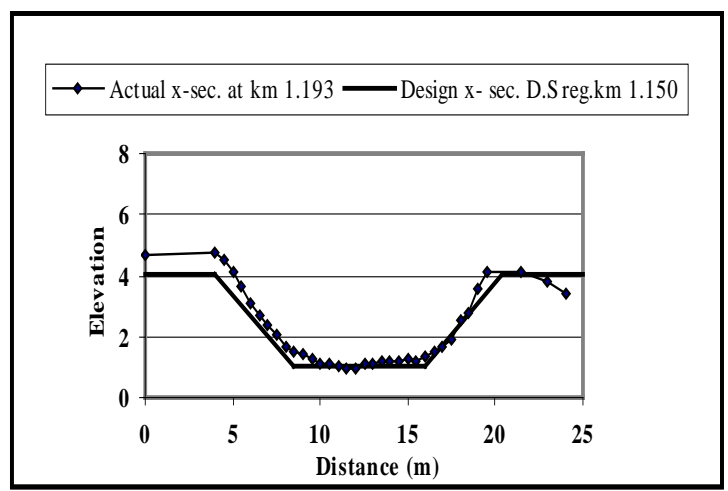

Fig. 2 Schematic drawing for Dakalt command area Dakalt canal is served by two main drains; No 7 drain on the right hand side and El-Raghama drain on the left hand side.

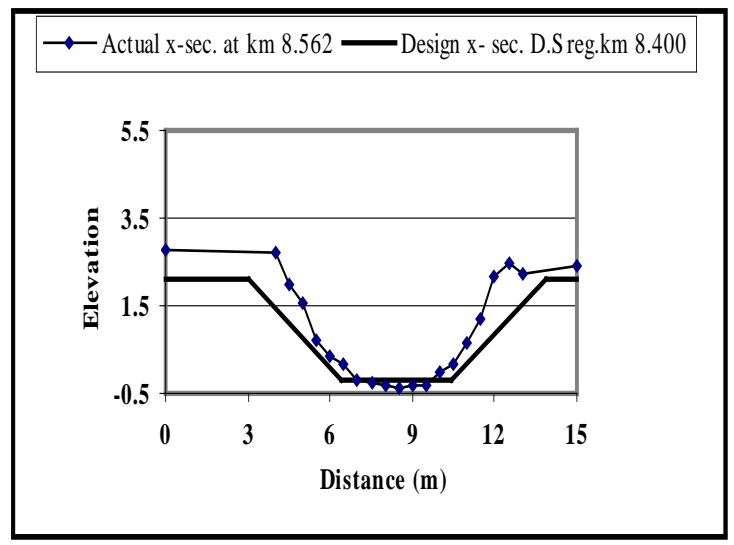

Fig. 3 Schematic drawing for Dakalt command area 


\section{RESULTS}

\subsection{Water levels}

From continuous recording and monitoring of actual water levels along Dakalt canal, it was found that, there were filling and emptying periods in the canal during a day. Generally, filling the canal occurs when delivered discharges are much than withdrawal by farmers, and emptying occurs when delivered discharges are less than withdrawal. These periods were varied along the canal reaches and from summer to winter. Filling periods were during night hours and emptying periods were during daylight hours.

For summer seasons, irrigation hours along the canal reaches were from about 6:00 am to about 7:00 pm, (Figures 4-6). There is irrigation breakdown during irrigation hours in the second and the third reaches, (Figures 5, 6). For winter seasons, irrigation hours were from about 8:00 am to 7:00 pm for the first reach, (Figure 4) .The rest of the day was the filling period, (Figures 4-6).

From Figures (4-6), it was found that average actual water levels were below the maximum and minimum design water levels during a day for the canal reaches during summer seasons. At the end of the filling periods, water levels did not reach the maximum design water levels, and during irrigation hours water levels were below the minimum design water levels. Except for the second reach during summer 2006 and 2007 some water levels were higher than the maximum design water levels at the end of filling periods, (Figure 5).

During irrigation hours average actual water levels at the upstream end of the canal reaches were (2.10), (1.28), and (0.71) and the minimum design water levels were (2.45), (1.38), and (1.05), respectively. Also actual average maximum water levels during filling periods at the upstream end of the canal reaches were (2.17), (1.40), and (0.83) and the maximum design water levels were (2.60), (1.40), and (1.10), respectively. Most of farmers scrambled to irrigate at the same period along the canal reaches. Actual behaviour of preferring the same hours for irrigation affected water levels to fall dramatically. Falling of water levels made famers feel dissatisfied, especially at the tail end reach. So that in summer, irrigations were broken down during irrigation hours in the second and third reaches, (Figures 5\&6).

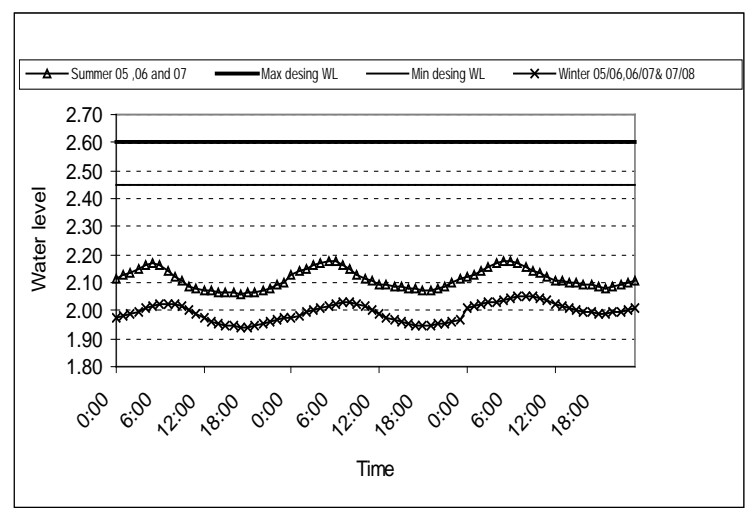

Fig. 4 Average water levels downstream gates km 1.150 during summer and winter

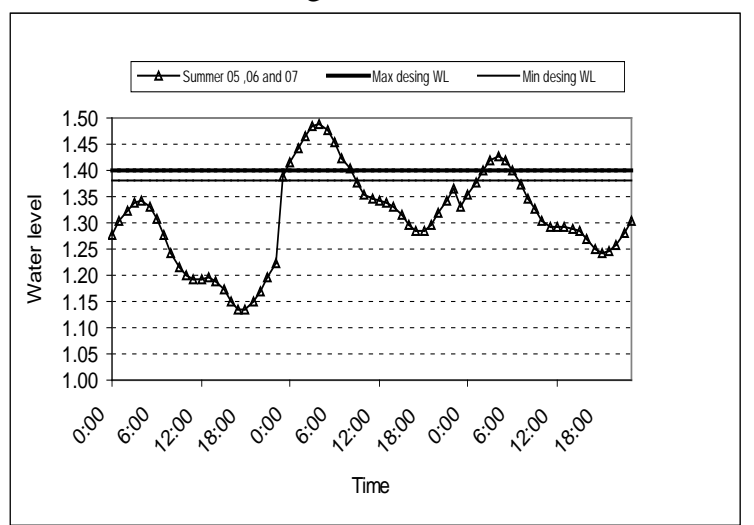

Fig. 5 Average water levels downstream gates km 5.150 during summer

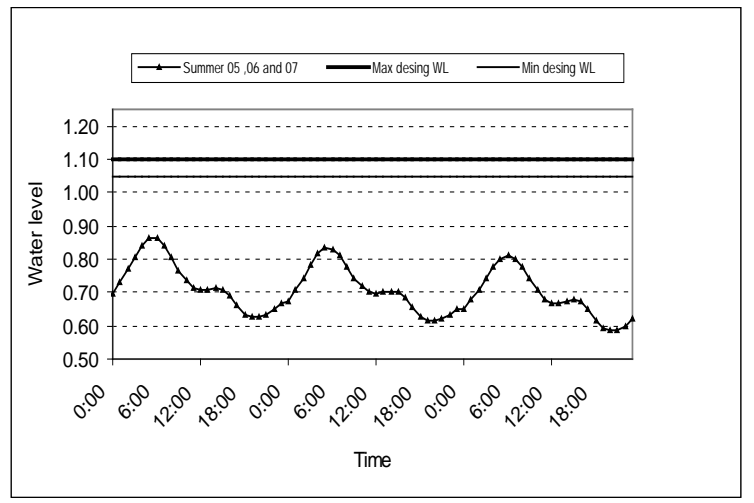

Fig. 6 Average water levels downstream gates $\mathrm{km}$ 8.400 during summer

\subsection{Results of field experiments 4.2.1 Water levels}

From the field experiments that were conducted during November 2006 and June 2007. Figures (7 \& 8) present average water levels downstream the first and the third automatic gates during November (representing winter season) and June (representing high consumption period) with maximum and minimum design water levels at each site. From the 
figures, the following could be observed:

In both regions, water levels were below minimum design water levels, but differences were higher at the tail end. In November, water levels decreased at the beginning of the head region to be between (1.95) and (2.07) and they were at the beginning of the tail region between (0.85) and (0.98). During June and at the head, water levels were between (2.14) and (2.26) and at the beginning of the tail reach, the values were between (0.26) and (0.60). The minimum design water levels were (2.45) and (1.05) at the beginning of head and tail regions, respectively.

Considering the diurnal changes, water levels reach their maximum values at the early hours of the morning during high consumption period. At the head, the highest value was at 5:00 AM and the lowest value was at 10:30 AM. At the beginning of the tail region, the maximum value was at 5:00 AM as well and the lowest value was at 7:30 PM. In winter, the time of the maximum value delayed. At the head, the highest value was at 8:30 AM and the minimum value was in 4:30 PM in both sites.

The variation between different days was small at the head and they increase at the beginning of the tail region as delivering water had a trend of the rotation especially during summer. In June, the coefficients of variation were between 0.09 and 0.13 at the head and between 0.76 and 1.65 at the beginning of the tail region. In November, the coefficients of variation were between 0.07 and 0.08 at the head and between 0.28 and 0.30 at the beginning of the tail region.

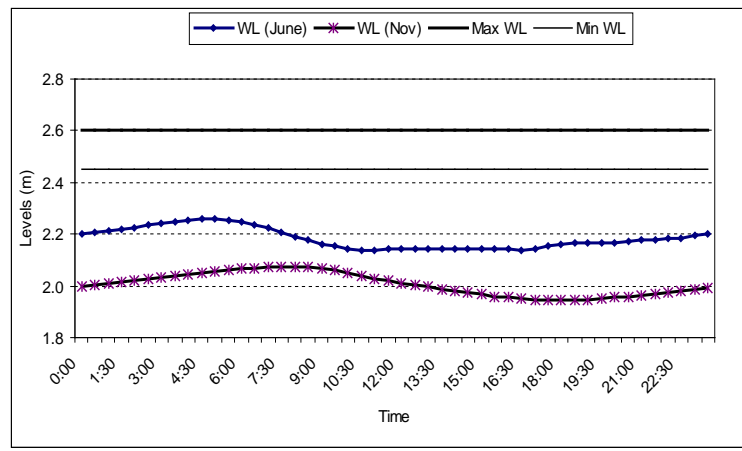

Fig. 7 Average water levels during June/2007and November 2006 months with maximum and minimum design water levels downstream first automatic gate in Dakalt canal

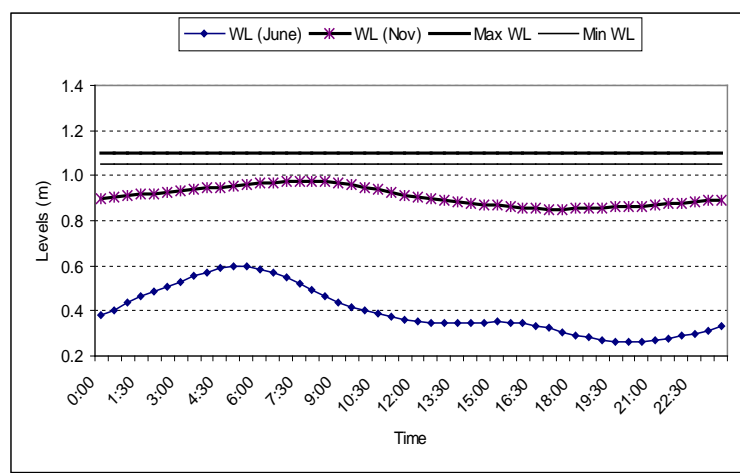

Fig. 8 Average water levels during June/2007 and November/2006 months with maximum and minimum design water levels downstream third automatic gate in Dakalt canal

\subsubsection{Discharges and irrigation pattern}

During summer experiment, it was found that discharge values ranged between 0.909 and 0.547 lps/fed for the first reach, 1.461 and $.965 \mathrm{lps} /$ fed for the second reach and 1.228 and $.235 \mathrm{lps} /$ fed for the tail reach. Discharges were increased in the last two days to recover water shortage during the first four days (Figure 9).Metawie, 1989 [1] stated that water duty for continues flow is $0.486 \mathrm{lps} / \mathrm{fed}$.Actual delivered discharges for the canal ranged between 0.645 and 0.849 , (Figure 9).It results in that, the actual delivered discharges for the canal are more than enough but there is a miss water allocation between reaches.

The opportunity of the tail farmers to irrigate was close to the opportunity of the head farmers during winter season. This could be observed from average water levels during winter seasons, (Figures 7, 8). In summer season, there was a big difference between both regions as could be observed from figures $(7,8)$. In summer experiment, $70 \%$ of the pumps in the head region were working in the forenoon hours. In the tail region, no improved pump was working in the first four days and some pumps begun to work in the last two days with the increase of the water supply at the head regulator to face water crises at the tail end (Figures 10,11). As was mentioned, some farmers' pumps were used in the tail region and they were not monitored. However, low water levels (Figures 7, 8) indicated that the consumption during the first four days of the experiment was very limited. It seemed to be that there was internal rotation between canal reaches.

From figures (12-14), it was found that withdrawal discharges were along the day hours and preferred irrigation periods were mostly the same for the head and the middle regions. No withdraw during the first four days by the single point lifting at the tail end due to water shortage. For the first and second reaches withdrawal discharges started from midnight to 4:00 am 
with very small amounts and rose significantly from about 4:00 am to 7:00 am to reach the maximum value and began to fall gradually till about 7:00 pm then started to fall clearly to reach minimum values at the end of the day. Averages withdraw discharges started from1.585 to $0.911 \mathrm{lps} /$ fed and from 1.708 to 1.218 lps/fed during preferred irrigation periods for the head and middle regions, respectively. During summer experiment, average withdraw discharge values were from 0.695 to $0.835 \mathrm{lps} /$ fed and average supply values were from 0.645 to $0.849 \mathrm{lps} / \mathrm{fed}$.

Figure (15) shows that actual withdrawal percentages along the day hours for the first and the second reaches. Although withdrawal periods continued along the day hours in these reaches, about $81.7 \%$ and $80.5 \%$ of actual withdrawal were from 7:00am to 7:00 pm. The remaining of withdrawal volume was during the rest of day hours.

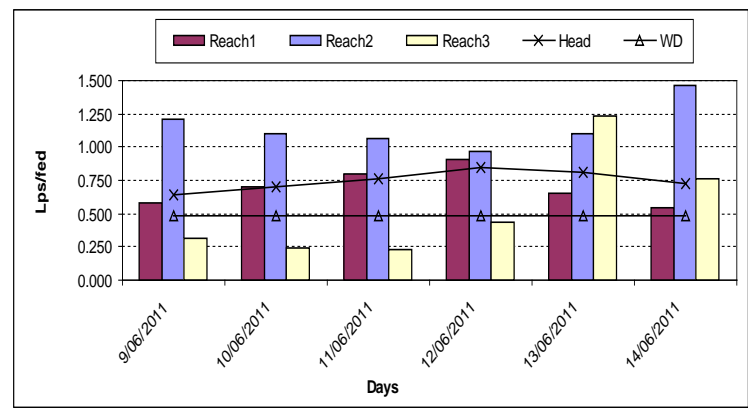

Fig. 9 Average actual discharge during summer experiment with average water duty

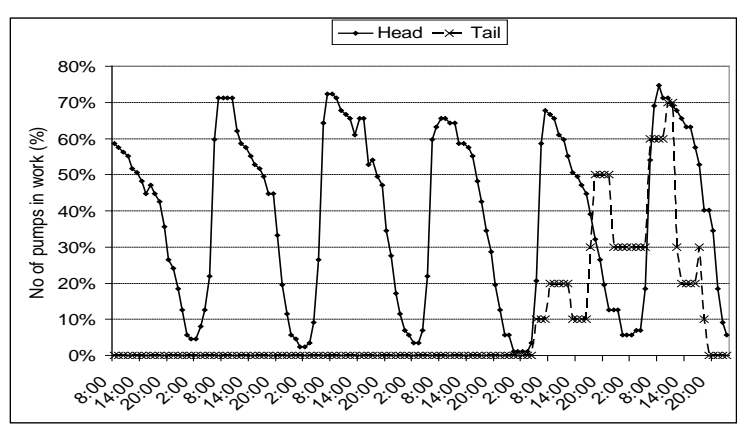

Fig. 10 Average percentage of pumps in work at the head and the tail end of Dakalt canal during summer experiment

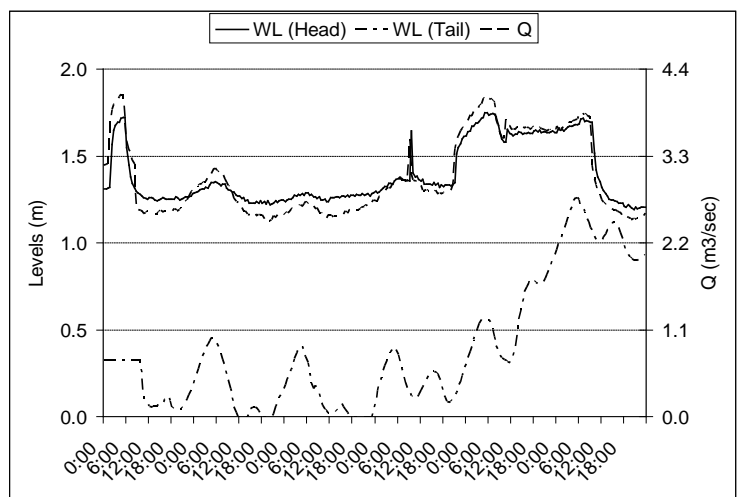

Fig. 11 Water levels at the beginning of the head and the tail regions of Dakalt canal during summer experiment

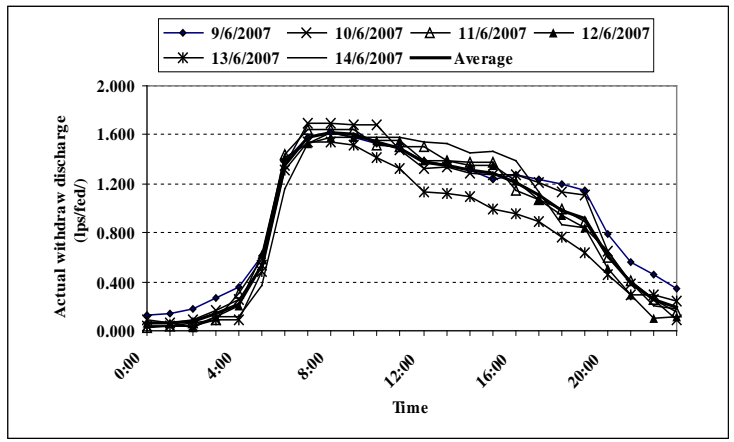

Fig. 12 Average hourly withdraw discharge at the head region of Dakalt canal during summer Experiment

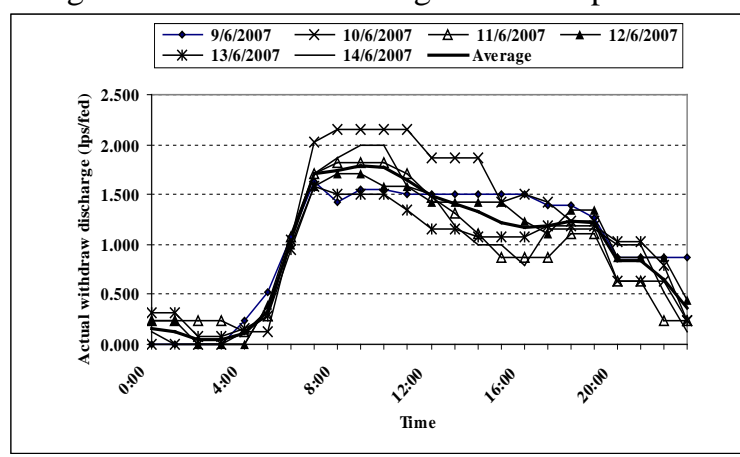

Fig. 13 Average hourly discharge withdraw at the middle region of Dakalt canal during summer Experiment

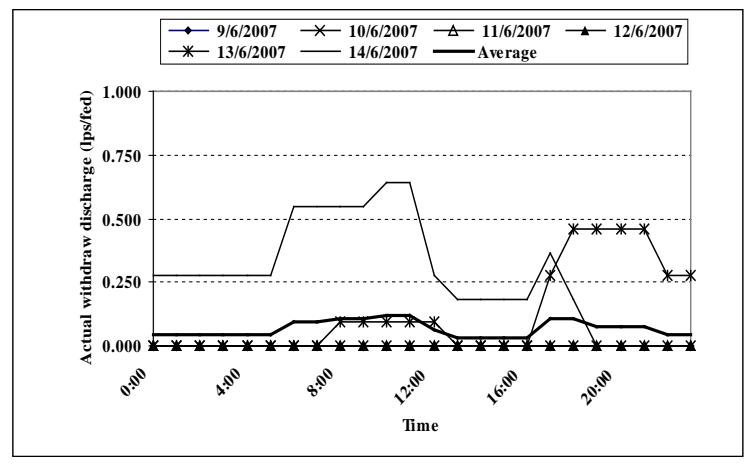

Fig. 14 Average hourly withdraw discharge at the tail region of Dakalt canal during summer Experiment 


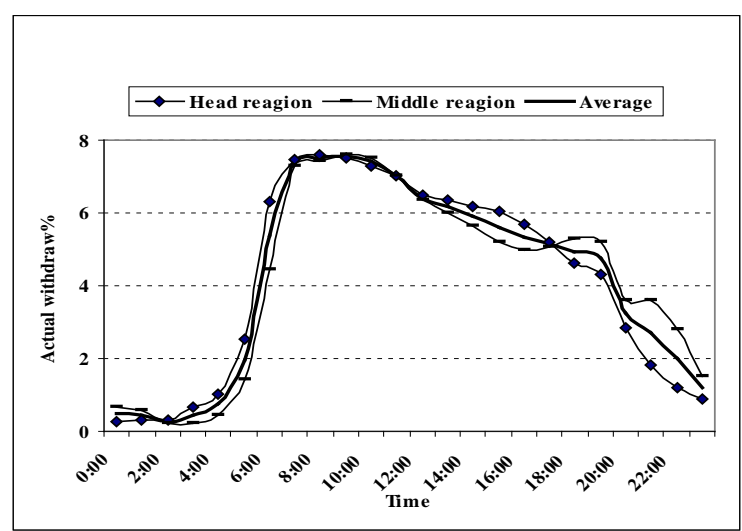

Fig. 15 Actual withdraw percentage on Dakalt canal during summer Experiment

4.3 Comparing design assumption with actual collected data

During the design of the improved canals in IIP1, the old lifting points were used in the design. It was assumed that the lifting points are working in the same time and for 16 hours with flexibility factor ranged between 1.5 for areas less than 200 feddans and 1.1 for areas exceeds 5000 feddans. The abstraction pattern has the cosine curve and it begins from 7:00 AM with 0.41 lit/fed/sec and increase gradually to $0.95 \mathrm{lit} / \mathrm{fed} / \mathrm{sec}$ between 2:00 and 3:00 PM and decreased gradually again until 11:00 PM. Most of the sub-branches were considered as one lifting point at the head of the sub-branch while simulating the flow to design the improved canal.

From figure (16), actual abstraction is completely different from the design values. The peak time of the actual abstractions was earlier than the peak time in the design one and the abstraction pattern during high consumption period was much higher than the design values. This change, with operating the canal based on maintaining downstream water levels, explains the water shortage at the tail end region.

On the other hand, considering sub-branches as one lifting point means decreasing the storage volume and therefore decreasing design water levels. This could explain the lower levels in the canal compared to the design values.

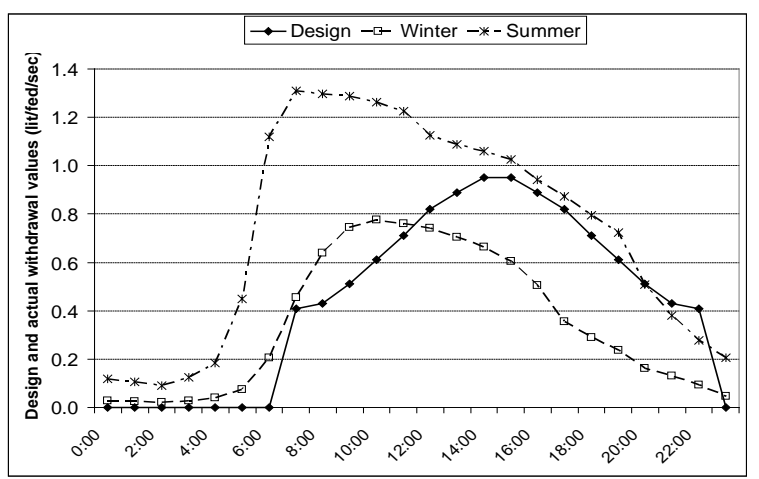

Fig.16 Actual withdraw and average consumption for Dakalt canal during summer experiment

\section{DISCUSSION AND RECOMMENDATION}

This study was conducted to illustrate the actual irrigation pattern in the improved canals. The study focuses on the withdraw pattern in the canal and its effect on the fluctuation of water levels and the ability to operate the canal properly to enhance the tail end situation. The study also discussed the differences between the design assumption and current collected data. The results showed the following:

- Irrigation was concentrated in the forenoon hours and almost stops during the night hours. about $80 \%$ of withdraw was between 7:00 am to7:00 pm in the head and middle regions

- The canal was not operated as design. The deviation from the design values increased during high consumption period and at the tail end.

- Irrigation pattern in the head regions affected water levels which created water shortage and nearly stopped irrigation in the tail end region.

- The actual abstraction pattern was different from the design assumption.

- The equity was missed between head and tail regions especially in high consumption period. During winter, irrigation crises decrease at the tail end region.

- The operation of the improved canals still follows the previous operating practices as could be observed in the second experiment. During this experiment, the tail end was facing water shortage event for few days before increasing water supply at the head regulator to solve the problem. .A kind of rotation still exists at the tail region despites the continuous opening of the canal.

- Low water levels at the tail end restricted the suitable operation of the lifting points. Some lifting points were totally stopped and the farmers were using their old pumps.

- In addition, low water levels increase the suction head of the pumps and therefore increase the oil consumption for the pumps, which has negative effect on the farmers.

- This inconvenient about the irrigation process increase the rejection of the project between the farmers and therefore resist the spread of the project in the old lands.

Therefore, it is important to set up a new operation strategy depending on internal rotation between single points lifting along the canal .The new internal rotation will be based on the actual consumption values and actual pattern of irrigation to avoid any problems at the tail ends of the improved canals. 


\section{REFERENCE}

[1] Abdel Fattah Metawie, (1989)."Feasibility of Local Off-Stream Storage Ponds to Reduce Discrepancies Between Supply and Demand."Ph.D, Colorado State University.

[2] Bert De Bievre; Andres Alvarado;Luis Timbe; Rolando Celleri and Jan Feyen (2003)."Night Irrigation Reduction for Water Saving in Medium - Sized Systems." Journal of Irrigation and Drainage Engineering, 129(2):108-116.

[3] Dia El-Din El-Quosy (1987)."A Method Of Saving Irrigation Water In The Arab Republic Of Egypt By Modifying Irrigation Rotation." Water Science Magazin National Water Research Center,Cairo, Egypt.

[4] Dorota Z. Haman and Stuart W. Styles (1999)."Problems of Irrigation in Developing Countries."Journal of Irrigation and Drainage Engineering, 125(1):1-6.

[5] El-Kady, J. Wolfe, and H. Wahby, "The rotation water distribution system vs. The continual flow water distribution system” technical report \# 20, EWUP, Egypt, April 1982.

[6] Egypt Water Use and Management Team (1984)."Findings Water Use and Management Project." National Water Research Center, Cairo, Egypt.

[7] Hvidt, M. "Water, Technology and Development - Upgrading Egypt's Irrigation System", Tauris Academic Studies, New York, 1998.
[8] L. Tinsley, A. Ismail, and M. El-Kady "A Method for Evaluating and Revising Irrigation Rotations”, technical report \# 48, EWUP, Egypt, December 1984.

[9] MacDonald \& Partners ltd "Rehabilitation and Improvement of Water Delivery Systems in Old Lands", United Nations Development Programme, May 1988.

[10] Paul R Cross (2000)."Benefits of Flexible Irrigation Water Supply." Journal of Irrigation and Drainage Engineering, 126(6):275-278.

[11] Robert Chambers (1986)."Canal Irrigation at Night." Journal of Irrigation and Drainage Systems, 1(1):45-73.

[12] Suni D. Gorantiwar,I an K, Smout, K Vairavamoorthy (2006)." Performance- Based Optimization of Land and wWater Resources Within Irrigation Schemes. I: Method" Journal of Irrigation and Drainage Engineering, 132 (4):332-340.

[13] Wadie F. Mankarious (1990)."Improvement Operation of Distribution Canals on Canals on Concept of Discharge Time function." Water Science magazine National Water Research Center, Cairo, Egypt.

[14] Water Management Research Institute "Monitoring and Evaluation of Irrigation Improvement Project First part (Final Findings)", 2008 .

[15] Willcocks, W. and M.A. Craig "Egyptian Irrigation", London : E. \& F.N. Spon, Ltd ; New York : Spon \& Chamberlain, 1913. 